\title{
Does thread shape affect the fixation strength of the bioabsorbable interference screws for anterior cruciate ligament reconstructions? A biomechanical study
}

\author{
Gerardo L. Garcés ${ }^{1 *}$ D, Oscar Martel², Alejandro Yánez² and Alberto Cuadrado²
}

\begin{abstract}
Background: The purpose of this study was to compare the biomechanical behaviour of two bioabsorbable interference screws with different geometries.

Methods: Two different pitch ( 2.5 and $5 \mathrm{~mm}$ ) bioabsorbable interference screws, both $9 \times 30 \mathrm{~mm}$, were tested. Tests were performed with forty bovine digital extensor tendons and skeletally mature porcine tibiae. Two protocols of cyclic tests at $1 \mathrm{~Hz}$ were performed: 1000 cycles from 50 to $250 \mathrm{~N}$, and 5000 cycles from 100 to $300 \mathrm{~N}$ ( $n=10$ for each type of test and screw). After the cyclic loading, a final ramp displacement until failure at $0.5 \mathrm{~mm} / \mathrm{s}$ was applied.

Results: The stiffness after the cyclic phase of the tests was not statistically different between the two screws (1000th cycle: $2.5 \mathrm{~mm}$ pitch $280.3 \pm 56.4 \mathrm{~N} / \mathrm{mm}, 5 \mathrm{~mm}$ pitch $275.2 \pm 65.0 \mathrm{~N} / \mathrm{mm}, P=.965 ; 5000$ th cycle: $2.5 \mathrm{~mm}$ pitch $281.3 \pm 66.4 \mathrm{~N} / \mathrm{mm}, 5 \mathrm{~mm}$ pitch $286.1 \pm 79.4 \mathrm{~N} / \mathrm{mm}, P=.814$ ). The yield load was not significantly different between the screws (1000 cycle tests: $2.5 \mathrm{~mm}$ pitch $482.2 \pm 120.2 \mathrm{~N}, 5 \mathrm{~mm}$ pitch $495.9 \pm 131.3 \mathrm{~N}, P=.508 ; 5000$ cycle tests: $2.5 \mathrm{~mm}$ pitch $476.4 \pm 65.3 \mathrm{~N}, 5 \mathrm{~mm}$ pitch $494.3 \pm 39.2 \mathrm{~N}, P=.391)$. No correlation was found between the insertion torque and yield load (1000 cycle tests, $R^{2}=0.013 ; 5000$ cycle tests, $R^{2}=0.006$ ).

Conclusions: The pitch of bioabsorbable interference screws does not seem to affect fixation strength. Also, the authors recommend not to use insertion torque alone to estimate the fixation strength.
\end{abstract}

Keywords: Anterior cruciate ligament, ACL reconstruction, Interference screw, Biomechanical testing

\section{Background}

The interference screw is the most commonly used fixation device in anterior cruciate ligament (ACL) reconstruction [1]. The screw is manufactured from titanium or a bioabsorbable material, but drawbacks have been reported for both. Bioabsorbable screws have been associated with tunnel widening, risk of screw failure, increased inflammatory response, and incomplete screw absorption, [2] while titanium screws have been associated with graft laceration and hindering magnetic resonance imaging (MRI) capture [3]. Clinical outcomes

\footnotetext{
* Correspondence: ggarces@imqc.es

'Department of Medical and Surgical Sciences, University of Las Palmas de Gran Canaria, Edificio de Ciencias de la Salud, Campus Universitario de San Cristobal, Trasera del Hospital InsularC/ Doctor Pasteur s/n, 35016 Las Palmas, Spain

Full list of author information is available at the end of the article
}

with titanium and bioabsorbable screws are comparable, [2-5] however the latter offers the additional benefits of allowing MRI, decreasing stress shielding by gradually transferring load during degradation, and theoretically minimizing the difficulty of revision surgery [6]. Therefore, the authors believe that bioabsorbable interference screws appear to be preferable to titanium screws.

Bioabsorbable interference screws are available in different diameters and lengths, with various thread geometries. In a comparative in vitro biomechanical study of different bioabsorbable and titanium interference screws, no differences were found between them [7]. Lately, a high pitch bioabsorbable interference screw, that allows insertion twice as fast as the traditional one, has been introduced. Although some studies have shown that thread geometry does not influence the biomechanical 
properties of an interference screw, this conclusion was based in one case on magnesium-based screws [8] and in other case on different buttresses screws, but with the same pitch [9].

One possible consequence of a higher pitch is a higher insertion torque, [10] and it is believed that the higher the insertion torque, the better the fixation quality $[11,12]$. However, several studies showed that the insertion torque does not predict the strength of the fixation with an interference screw in ACL reconstruction [13, 14]. The effect of screw pitch remains an open issue.

The purpose of this study was to compare the biomechanical behaviour of two bioabsorbable interference screws made of the same material but with different geometries. Our hypothesis was that the two screws had similar in vitro biomechanical properties. A secondary purpose of the study was to determine if a correlation exists between the insertion torque and fixation strength in an ACL reconstruction when bioabsorbable interference screws were used.

\section{Methods}

In this study, forty bovine digital extensor tendons and skeletally mature porcine tibiae were used. Tendons were harvested immediately after the slaughter of the bovines, and they were wrapped in gauze soaked in normal saline and placed in plastic bags. Porcine tibiae used for testing were taken from animals around 6 months old, obtained from a local slaughterhouse after having been sacrificed for human consume. All of them were fed under the same conditions and was assumed that bone density was similar in all the specimens. The fibula and all soft tissue and muscles were removed. The distal end of the tibia was sectioned to attach the bone to a custom-made jaw. Both tendons and bones were stored at $-20^{\circ} \mathrm{C}$. Twelve hours before testing, the tissue was thawed at room temperature and kept moist throughout the handling and testing period.

A custom-made tendon caliper was used to measure the diameter of the grafts. In order to compare both fixation systems in the same conditions, only folded tendons passing the $9-\mathrm{mm}$ bore, but not the $8.5 \mathrm{~mm}$ one, were used. Tendon ends were sutured to facilitate handling. During the ACL reconstruction, the bone was attached to a vice. In the tibia, a $\varnothing 9-\mathrm{mm}$ bonny tunnel (C-Reamer, Conmed Linvatec, Largo, FL, USA) was created at a $45^{\circ}$ angle from the longitudinal axis. The entrance point was the medial side of the tibial tuberosity and the exit point was the upper part of the tibia, approximately at the natural insertion point of the ACL.

Two types of $9 \times 30 \mathrm{~mm}$ bioabsorbable screws from the same manufacturer (DePuy Mitek, Inc. Raynham, MA, USA) were chosen for this study. The $2.5 \mathrm{~mm}$ pitch Milagro interference screw and the $5 \mathrm{~mm}$ pitch Milagro Advance interference screw were used (Fig. 1). Both screws are made of Biocryl Rapide (30\% $\beta$-tricalcium phosphate, $70 \%$ poly-lactide co-glycolide).

Each reconstruction was performed with a folded tendon with its end sutured to make a double-looped graft. The graft was then inserted into the tunnel with the assistance of the sutures. An approximately $30-\mathrm{mm}$ loop extended out from the upper part of the tibia, simulating the natural ACL intra-articular length [15]. The interference screw was then inserted using a $3.5 \mathrm{~mm}$ hex key. During insertion, the loop was fixed, simulating the femoral fixation and manual tension was applied to the free end of the tendon as in usual surgical routine. The maximum insertion torque was recorded using a digital torque meter (DR-2453, Lorenz Messtechnik GmbH, Alfdorf, Germany) mounted on the hex key.

Each specimen was placed on a testing machine (EFH/5/FR, Microtest S.A., Madrid, Spain). The tibia was fixed at the lower part of the machine with a custom-made jaw that holds it at an angle of $45^{\circ}$ to the vertical axis and allows it to be pulled in the bonny tunnel direction, which is the worst-case loading scenario for the reconstructed ACL. A hook in the upper grip of the testing machine was used to hold the graft loop (Fig. 2).

Following ACL reconstruction, the specimens were tested. Two types of cyclic fatigue tests with sinusoidal variation in load at $1 \mathrm{~Hz}$ were performed: 1) 1000 cycles, $50-250 \mathrm{~N}$, and 2) 5000 cycles, $100-300 \mathrm{~N}$ (10 specimens for each type of test and screw). For both type of tests, the minimum load $(50 \mathrm{~N}$ or $100 \mathrm{~N}$, for tests of type 1 and 2, respectively) was applied for $60 \mathrm{~s}$ (s), after which the cyclic testing was performed. The first ten cycles were considered preconditioning. After the cyclic loading, the load was again held at $50 \mathrm{~N}$ or $100 \mathrm{~N}$ for $60 \mathrm{~s}$ and then a final ramp displacement until failure at $0.5 \mathrm{~mm} / \mathrm{s}$ was

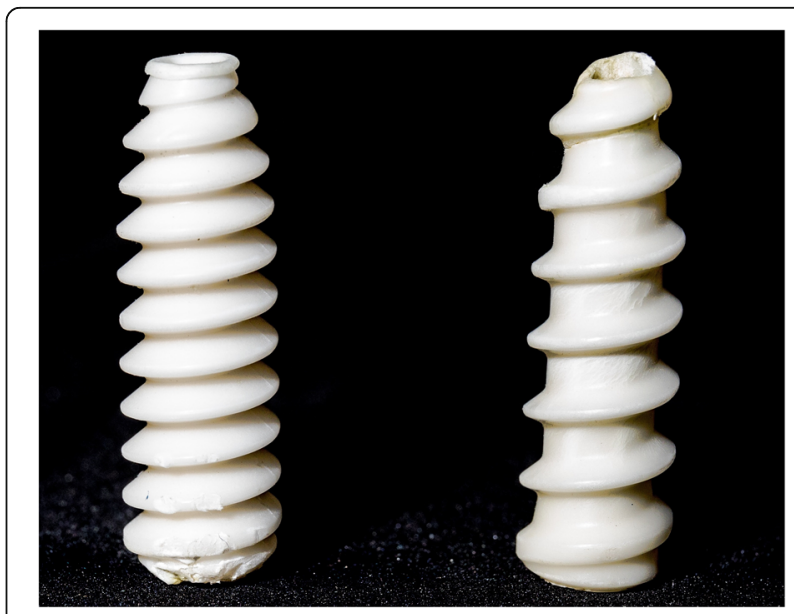

Fig. 1 Bioabsorbable interference screws tested. $2.5 \mathrm{~mm}$ pitch Milagro (left) and $5 \mathrm{~mm}$ pitch Milagro Advance (right) 


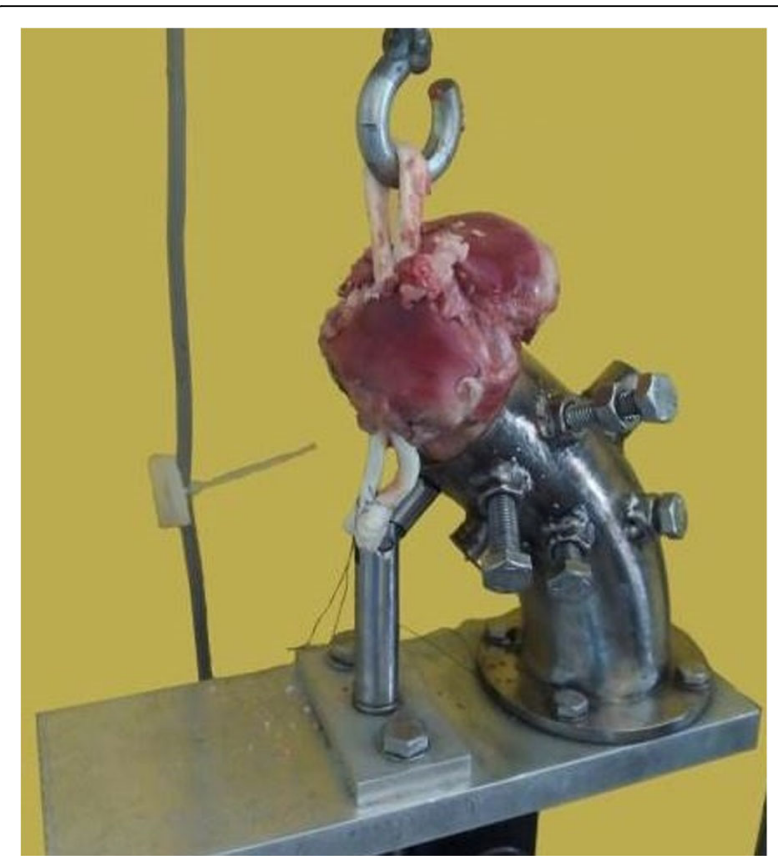

Fig. 2 Tibia with the ACL reconstruction performed and inserted in a custom-made jaw mounted at the lower part of the testing machine. The graft loop was attached to the upper grip via a hook

applied. In all cyclic tests, a $1 \mathrm{~Hz}$ load frequency was used to reproduce normal walking frequency [16].

The $50-250 \mathrm{~N}$ load range simulated forces in the ACL during terminal passive extension of the knee [17]. The 1000 cycles approximated one week of flexion-extension loading on an ACL reconstruction [18]. This testing simulated an aggressive, but typical, rehabilitation protocol after an ACL reconstruction [19]. The $300 \mathrm{~N}$ load is the upper force expected during normal daily activities, so cyclic testing up to $300 \mathrm{~N}$ simulated peaks occurring postoperatively [16]. The 5000 cycles represented an extreme test of the free graft fixation stability [20]. This test represented the worst-case scenario for an ACL reconstruction, i.e., lack of a rehabilitation protocol and early normal daily activities.

Data from 1 cycle every 100 cycles (for the 1000 cycle tests) or every 500 cycles (for the 5000 cycle tests) were recorded at $100 \mathrm{~Hz}$. Load and displacement were obtained from the load cell and displacement sensor of the testing machine, respectively. In the cyclic phase of each test, stiffness and displacement results were obtained (Fig. 3). Stiffness was defined as the slope of the line connecting the maximum and minimum points of the load-displacement graft in a complete cycle. Stiffness was determined at the 100th and 1000th cycle for the 1000 cycle tests and at the 500th and 5000th cycle for the 5000 cycle tests. Displacement was set to zero after the preconditioning period and was obtained from the same cycles as the stiffness values. All displacements were measured at minimum cyclic load.

During application of the final monotonic tensile load, pull-out stiffness, yield load, and ultimate failure load were measured (Fig. 4). Pull-out stiffness was determined as the slope of the linear region of the force-displacement curve. Linearity was assumed when Pearson's correlation was equal to or greater than 0.99 . Yield load was determined as the load corresponding to the intersection point of the force-displacement curve and the stiffness determination line offset $0.06 \mathrm{~mm}$, which corresponded to a deformation of $0.2 \%$ of the graft length. Ultimate failure load was the maximum load registered during the test.

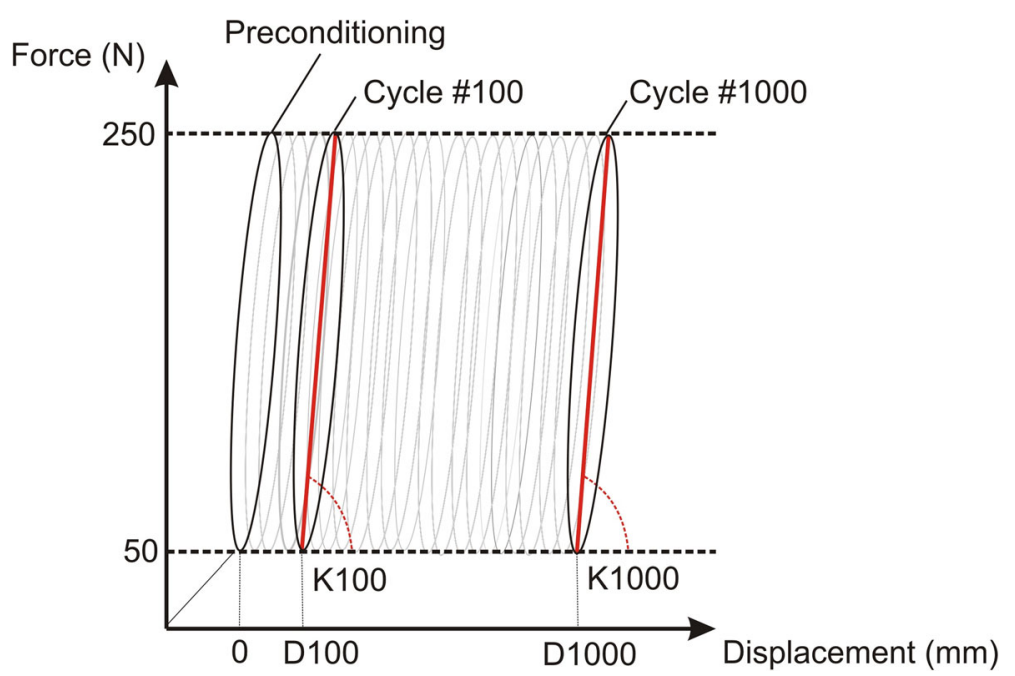

Fig. 3 Force vs. displacement plot during cyclic test phase, showing the measured displacement. The stiffness $(K)$ is showed as the slope of the line connecting the maximum and minimum points in a complete cycle 


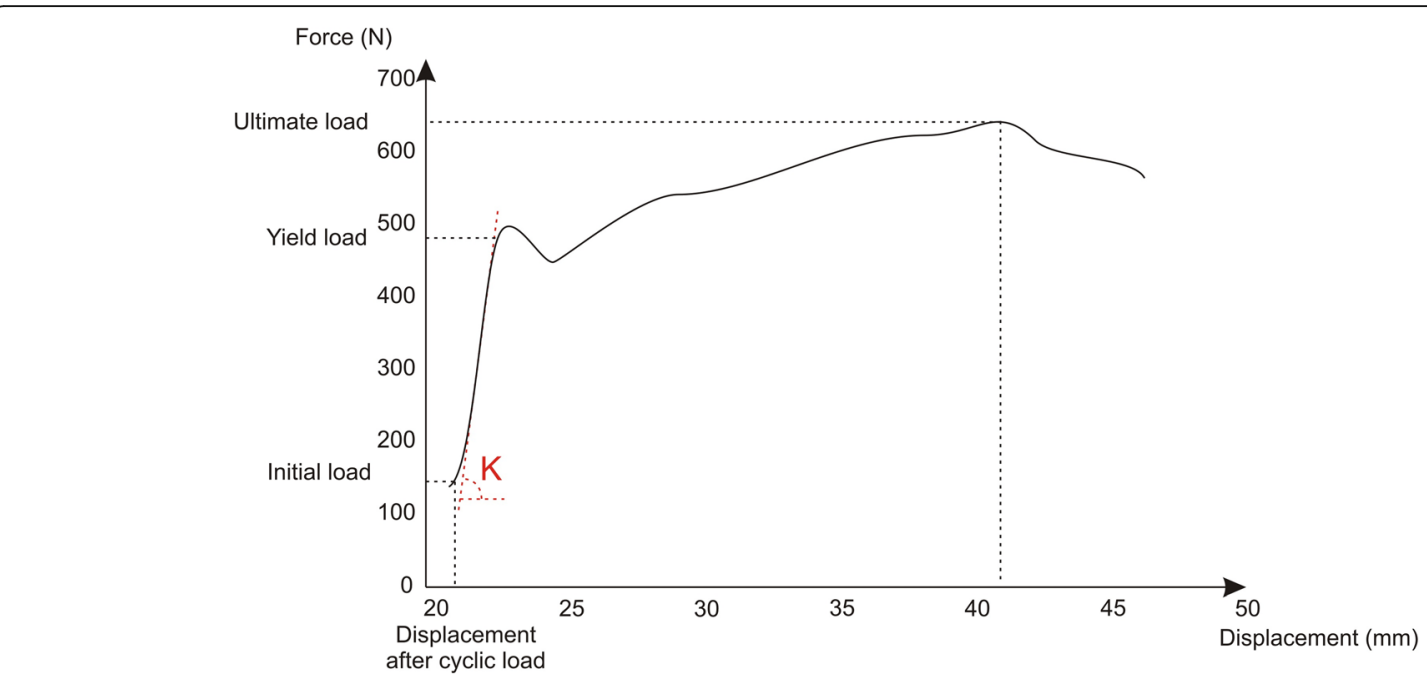

Fig. 4 Force vs. displacement plot during final monotonic tensile load, showing yield load, ultimate failure load and pull-out stiffness (K) as the slope of the linear region of the graph

Data were analyzed using SPSS v 24.0 (IBM, Chicago, IL, USA). An a priori power analysis ( $\mathrm{G}^{*}$ Power 3.1.9.2, Heinrich-Heine-Universität, Düsseldorf, Germany) using the standard deviation and mean from a previous similar study with a bioabsorbable interference screw by Aga et al. [21] was conducted to determine the sample size. A significance level $(\alpha)$ of .05 , a power of 0.8 , a standard deviation and an anticipated effect size for ultimate load of $96 \mathrm{~N}$ and $120 \mathrm{~N}$, respectively, were used. According to this, a total sample size of 20 was required, so $n=10$ per group was used, a group size also used by many authors [21-23]. The behaviour of the two screws was compared using a Mann-Whitney $U$ test because normality of data cannot be assumed. When comparing stiffness values at different cycles, Kruskal-Wallis tests were conducted for the same reason. $p$-values $\leq .05$ were regarded as significant. The relationship between the insertion torque and yield load was studied by linear regression to obtain the coefficient of determination $\left(R^{2}\right)$.

\section{Results}

Insertion torque in tests performed with the $2.5 \mathrm{~mm}$ pitch screw group $(n=20)$ was $1.89 \pm 0.46 \mathrm{Nm}$, and in the $5 \mathrm{~mm}$ pitch screw group $(\mathrm{n}=20)$ was $1.57 \pm 0.44 \mathrm{~N}$ $\mathrm{m}$, showing no significant difference $(p=.415)$.

\section{Cycle, $50-250 \mathrm{~N}$ tests}

One specimen of the $2.5 \mathrm{~mm}$ pitch group failed at 11 cycles and one specimen of the $5 \mathrm{~mm}$ pitch group failed at 214 cycles. In both cases the failure mode was the pull-out of one strand of the tendon, while the screw remained in its original position. The remaining nine specimens in each of the two screw groups successfully completed the cyclic phase of the test. In the final tensile test the principal failure mode was the pull-out of one or two branches of the tendon; however, in two cases for both screws, the tendon ruptured. The tendon ruptures were associated with higher ultimate loads (887 $\mathrm{N}$ and $943 \mathrm{~N}$ with the $2.5 \mathrm{~mm}$ pitch screw, and $840 \mathrm{~N}$ and $863 \mathrm{~N}$ with the $5 \mathrm{~mm}$ pitch screw). In all cases, no noticeable displacement of the screw was observed.

The results obtained from the nine valid tests are shown in Table 1 . As the $p$-values show, no significant differences were found between the two screw groups. Stiffness at the 100th cycle, 1000th cycle, and pull-out showed no significant difference, both for the $2.5 \mathrm{~mm}$ pitch $(p=.565)$ and for the $5 \mathrm{~mm}$ pitch $(p=.476)$ screw. The coefficient of determination between insertion torque and yield load (both screws together, $n=18$ ) was $R^{2}=.013$, indicating that the two variables are not related.

Table 1 Results of the 1000 cycles tests for both screws

\begin{tabular}{llll}
\hline & $2.5 \mathrm{~mm}$ pitch & $5 \mathrm{~mm}$ pitch & $p$ \\
\hline Number of valid samples & 9 & 9 & \\
Maximum insertion torque $(\mathrm{N} \mathrm{m})$ & $1.74 \pm 0.47$ & $1.86 \pm 0.34$ & \\
Stiffness at 100th cycle (N/mm) & $256.4 \pm 50.7$ & $259.4 \pm 69.4$ & .757 \\
Stiffness at 1000th cycle (N/mm) & $280.3 \pm 56.4$ & $275.2 \pm 65.0$ & .965 \\
Displacement at 100th cycle (mm) & $1.35 \pm 1.15$ & $1.49 \pm 2.21$ & .508 \\
Displacement at 1000th cycle (mm) & $6.25 \pm 5.66$ & $5.13 \pm 4.56$ & .757 \\
Yield load (N) & $482.2 \pm 120.2$ & $495.9 \pm 131.3$ & .508 \\
Pull-out stiffness (N/mm) & $277.8 \pm 71.7$ & $244.5 \pm 64.6$ & .200 \\
Ultimate failure load $(\mathrm{N})$ & $656.6 \pm 178.7$ & $648.9 \pm 169.7$ & .965 \\
\hline
\end{tabular}

Data are presented as mean \pm SD 


\section{Cycle, $100-300 \mathrm{~N}$ tests}

One specimen with the $2.5 \mathrm{~mm}$ pitch screw failed at 3205 cycles, while four of the specimens with the $5 \mathrm{~mm}$ pitch screw failed before the 5000th cycle (failure at 39, 326 , 586, and 3344 cycles). The failure mode of these specimens was the pull-out of one or two branches of the tendon. The mode of failure in the specimens tested to pull-out was pull-out of one or two branches of the tendon. The results obtained from the valid tests are shown in Table 2. No significant differences $(p>.05)$ were found between the two screw groups, and the coefficient of determination between insertion torque and yield load $\left(R^{2}=.006\right.$, both screws together, $\left.n=15\right)$ indicated no relationship between the two variables. Stiffness at the 500th cycle, 5000th cycle, and pull-out showed no significant difference, both for the $2.5 \mathrm{~mm}$ pitch $(p=.852)$ and for the $5 \mathrm{~mm}$ pitch $(p=.459)$ screw.

Comparing the 1000 cycle tests with the 5000 cycle tests, no significant difference was found in the yield load for both screws $(p=.791$ and $p=.556$ and for the $2.5 \mathrm{~mm}$ pitch and the $5 \mathrm{~mm}$ pitch screw, respectively).

\section{Discussion}

The main finding of this study was that the $2.5 \mathrm{~mm}$ pitch and the $5 \mathrm{~mm}$ pitch screws have the same biomechanical performance under a simulated rehabilitation protocol. Therefore, the thread geometry seems to have no influence on the initial biomechanical properties of an ACL reconstruction with a bioabsorbable interference screw. his conclusion is similar to that obtained with magnesiumbased screws [8] and with different buttresses screws [9].

A load protocol of $50-250 \mathrm{~N}$ over 1000 cycles represents an aggressive, but typical, rehabilitation protocol [19]. During our tests, 10\% of each type of screw failed, which is a similar failure ratio reported by other researchers that used interference screws and similar load protocols $[15,18]$. In contrast, a load protocol of $100-300 \mathrm{~N}$ over 5000 cycles represents a return to normal daily activities. In these tests, $10 \%$ of the $2.5 \mathrm{~mm}$ pitch

Table 2 Results of the 5000 cycles tests for both screws

\begin{tabular}{llll}
\hline & $2.5 \mathrm{~mm}$ pitch & $5 \mathrm{~mm}$ pitch & $p$ \\
\hline Number of valid samples & 9 & 6 & \\
Maximum insertion torque $(\mathrm{N} \mathrm{m})$ & $2.01 \pm 0.45$ & $1.40 \pm 0.33$ & \\
Stiffness at 500th cycle $(\mathrm{N} / \mathrm{mm})$ & $270.1 \pm 55.7$ & $261.0 \pm 69.6$ & .906 \\
Stiffness at 5000th cycle $(\mathrm{N} / \mathrm{mm})$ & $281.3 \pm 66.4$ & $286.1 \pm 79.4$ & .814 \\
Displacement at 500th cycle $(\mathrm{mm})$ & $1.56 \pm 0.78$ & $1.84 \pm 1.20$ & .814 \\
Displacement at 5000th cycle $(\mathrm{mm})$ & $11.95 \pm 14.11$ & $6.97 \pm 5.74$ & .724 \\
Yield load $(\mathrm{N})$ & $476.4 \pm 65.3$ & $494.3 \pm 39.2$ & .391 \\
Pull-out stiffness $(\mathrm{N} / \mathrm{mm})$ & $259.9 \pm 53.4$ & $236.5 \pm 48.6$ & .886 \\
Ultimate failure load $(\mathrm{N})$ & $586.8 \pm 44.9$ & $619.1 \pm 127.6$ & .568 \\
\hline
\end{tabular}

Data are presented as mean \pm SD screws and $40 \%$ of the $5 \mathrm{~mm}$ pitch screws failed, although among those that successfully completed the cyclic testing, there was no significant difference between the two screws. However, the higher failure rate in the $5 \mathrm{~mm}$ pitch group leads us to suggest that screws with a very high pitch should not be used if a lack of a rehabilitation program is expected.

Cyclic testing was used to study stiffness and displacement. Stiffness was obtained because the goal of an ACL reconstruction is to restore normal knee kinematics, and matching the intact ACL stiffness is more important than achieving high ultimate failure load $[24,25]$. Previous reported stiffness of the intact ACL in young specimens was $242 \pm 28 \mathrm{~N} / \mathrm{mm}$ [26] and $306 \pm 80 \mathrm{~N} / \mathrm{mm}$ [27]. In our tests, stiffness values ranging from $256.4 \pm 50.7 \mathrm{~N} / \mathrm{mm}$ to $286.1 \pm 79.4 \mathrm{~N} / \mathrm{mm}$ were achieved, so both screws are suitable for ACL reconstructions. In addition, the stiffness remained stable during cyclic loading in all tests with both types of screws. Comparing the two screws, no significant differences were observed between the $2.5 \mathrm{~mm}$ pitch and $5 \mathrm{~mm}$ pitch screw for stiffness values measured at 100 cycles, 1000 cycles, 500 cycles, and 5000 cycles.

Permanent, or residual, displacement of the graft was measured, because it indicates whether there is any increase in laxity of the fixation system as the number of load cycles increases. No significant difference between the displacements of both types of screws was observed. However, large increases in displacement were observed between cycle 100 and 1000, and between cycle 500 and 5000 for both types of screws. Using a similar load protocol $(5000$ cycles between 50 and $250 \mathrm{~N}$ ) and a different bioabsorbable interference screw, a previous study reported residual displacements of $9.7 \pm 4.9 \mathrm{~mm}$ and $10.5 \pm 6.1 \mathrm{~mm}$, for screws with diameters of $10 \mathrm{~mm}$ and $11 \mathrm{~mm}$, respectively [15]. Smaller displacement at the 1000th cycle in an ACL reconstruction using the $2.5 \mathrm{~mm}$ pitch Milagro screw $(2.42 \pm 1.36 \mathrm{~mm})$ was reported, but a lower load range (20-150 N) was used [28].

Pull-out tests measure the remaining bearing capacity of the fixation system, which is related to the ability of the reconstruction to withstand a traumatic event [29]. Stiffness, yield load, and ultimate failure load were obtained in the pull-out phase of each test. Pull-out stiffness showed no significant difference from the stiffness at the initial (100th or 500th) and the final (1000th or 5000th) cycle, for both types of test and screw. This is expected, since the pull-out test can be considered the last cycle of the test.

Yield load was obtained from the graph because the authors believe that load best represents the fixation system failure load, since elongation increases very rapidly after this load, and may represent clinical failure. This assumption is consistent with a number of other 
published studies [15, 30-32]. No significant difference was observed in the yield load between the 1000 cycle and 5000 cycle tests, for both types of screw. These results suggest that the ability to withstand load, among those specimens that survived the cyclic phase of the test, is not affected by the number of cycles. The authors believe that the ultimate failure load should not be used to assess a fixation system; however, the ultimate failure load for comparison with other studies has been reported. The authors do not believe that the ultimate failure load is an appropriate measure of failure because it can only be reached at such a high slippage level that a clinical ACL reconstruction would be considered as having already failed.

Insertion torque necessary to place the interference screw is statistically the same with both screws, so the surgeons "feel" the same. However, the use of insertion torque as the fixation strength predictor remains a contentious issue, because some studies have shown that the insertion torque affects the load capacity of a fixation system, $[11,12]$ while others indicate that there is no relationship between the load and the insertion torque $[13,14]$. The relationship between the maximum insertion torque and the yield load was studied and no significant correlation was found. The authors believe that the insertion torque should not be used as an indicator of the quality of the fixation, at least if screw divergence has not been discarded by X-ray images.

The reason why the pitch does not affect the results remains unclear. Theoretically, the higher the pitch, the greater the insertion torque [10] and the lower the pitch, the greater the pull-out strength [33]. However, the results obtained in this study did not show any of those effects, probably because the final bone-screwgraft interface is quite heterogeneous and, therefore, the screw pitch does not play an essential role.

There are some limitations to this study. First, porcine tibiae and bovine digital extensor tendons were used instead of cadaveric specimens. The bovine tendon was used because it has similar biomechanical properties as human double-looped semitendinosus and gracilis grafts [34]. A tibia instead of a femur was used because the tibial fixation site has been reported as the weakest point in ACL reconstructions [21,35]. The porcine tibia is a widely used model in ACL biomechanical tests because of its availability and because its mechanical properties have greater uniformity than those of the human bones normally available, $[7,21,36]$ but concerns exist about its use. It has been suggested that the mechanical properties of a fixation method may not be the same in human tissue as in animal tissue [31]. Another concern is that graft slippage is underestimated and the failure load of the soft tissue graft is overestimated when porcine tibia is utilized compared with young human cadaver tibia [30]. However, like previous studies, [14, 15] the authors believe that since this is a comparative study, the differences between the two screws would also exist in human tissue and the conclusions are therefore valid.

Use of metallic screw was not considered, since this work aimed to compare fixation strength of ACL reconstructions with screws of different pitch and clinical outcomes with titanium and bioabsorbable screws are comparable [2-5].

A second limitation is that this was an in vitro study, so real clinical conditions such as biological osseointegration between bone and graft were not replicated. However, in this study, the main interest was the initial mechanical properties of the ACL reconstruction fixation system and an in vitro study is the gold standard for estimating these properties. Further in vivo studies would be needed to investigate whether there is a difference between the biological behavior of the two types of screws. Another limitation was that pull-out was in the tibial tunnel direction, representing the worst-case scenario, so nothing is known about the possible stress shielding that occurs at the edge of the hole and the exact behavior of the screws during actual flexion-extension knee movement. Again, the authors believe that the conclusions of this study are still valid because the testing conditions for the two screws were the same.

\section{Conclusions}

Thread shape of bioabsorbable interference screws does not seem to affect fixation strength. Despite their significant geometric differences, both interference screws had similar and acceptable biomechanical behavior, so both are suitable to be used in an ACL reconstruction. Therefore, the use of a higher pitch interference screw allows a faster insertion and do not compromise the fixation strength. Insertion torque alone should not be used to estimate the fixation strength because no correlation was found between the insertion torque and the yield load.

\section{Abbreviations}

ACL: Anterior cruciate ligament; Hz: Hertz; mm: Millimeters; MRI: Magnetic resonance imaging; N: Newtons; N/mm: Newtons/millimeter; Nm: Newtons meter; R2: Coefficient of determination; s: Seconds; SD: Standard deviation

\section{Acknowledgements}

We thank DePuy Mitek Inc., for providing the screws for this study.

\section{Funding}

This work was supported by the Mechanical Engineering Department of the University of Las Palmas de Gran Canaria (Spain) and a Research Project signed by Traumaquir SL, Fundación Parque Científico Tecnológico and University of Las Palmas de Gran Canaria (ref 2015/44). None of the funding institutions participated in any way in the design of the study and collection, analysis, and interpretation of data and in writing the manuscript.

Availability of data and materials

The datasets used and analysed during the current study are available from the corresponding author on reasonable request. 


\section{Authors' contributions}

GG and OM designed the study and carried out the tests. AC performed the statistical analysis and wrote the results section. AY was a major contributor in writing the manuscript and drawing conclusions. All authors read and approved the final manuscript.

\section{Ethics approval and consent to participate}

Not applicable.

\section{Consent for publication}

Not applicable.

\section{Competing interests}

The authors declare that they have no competing interests.

\section{Publisher's Note}

Springer Nature remains neutral with regard to jurisdictional claims in published maps and institutional affiliations.

\section{Author details}

'Department of Medical and Surgical Sciences, University of Las Palmas de Gran Canaria, Edificio de Ciencias de la Salud, Campus Universitario de San Cristobal, Trasera del Hospital InsularC/ Doctor Pasteur s/n, 35016 Las Palmas, Spain. ${ }^{2}$ Department of Mechanical Engineering, University of Las Palmas de Gran Canaria, Edificio de Ingenierías, Campus de Tafira, 35017 Las Palmas, Spain.

Received: 12 October 2018 Accepted: 28 January 2019 Published online: 08 February 2019

\section{References}

1. Chechik O, Amar E, Khashan M, Lador R, Eyal G, Gold A. An international survey on anterior cruciate ligament reconstruction practices. Int Orthop. 2013;37:201-6. https://doi.org/10.1007/s00264-012-1611-9.

2. Emond CE, Woelber EB, Kurd SK, Ciccotti MG, Cohen SB. A comparison of the results of anterior cruciate ligament reconstruction using bioabsorbable versus metal interference screws: a meta-analysis. J Bone Joint Surg Am. 2011;93:572-80. https://doi.org/10.2106/JBJS.J.00269.

3. Arama Y, Salmon LJ, Sri-Ram K, Linklater J, Roe JP, Pinczewski LA. Bioabsorbable versus titanium screws in anterior cruciate ligament reconstruction using hamstring autograft: A prospective, blinded, randomized controlled trial with 5-year follow-up. Am J Sports Med. 2015;43:1893-901. https://doi.org/10.1177/0363546515588926.

4. Papalia R, Vasta S, D'Adamio S, Giacalone A, Maffulli N, Denaro V. Metallic or bioabsorbable interference screw for graft fixation in anterior cruciate ligament (ACL) reconstruction? Br Med Bull. 2014;109:19-29. https://doi.org/ 10.1093/bmb/ldt038

5. Myers $P$, Logan M, Stokes A, Boyd K, Watts M. Bioabsorbable versus titanium interference screws with hamstring autograft in anterior cruciate ligament reconstruction: a prospective randomized trial with 2-year follow-up. Arthroscopy. 2008;24:817-23. https://doi.org/10.1016/j.arthro.2008.02.011.

6. Cox CL, Spindler KP, Leonard JP, Morris BJ, Dunn WR, Reinke EK. Do newer-generation bioabsorbable screws become incorporated into bone at two years after $A C L$ reconstruction with patellar tendon graft?: a cohort study. J Bone Joint Surg Am. 2014;96:244-50. https://doi.org/10. 2106/JBJS.L.01652

7. Ettinger M, Schumacher D, Calliess T, Dratzidis A, Ezechieli M, Hurschler C, Becher $\mathrm{C}$. The biomechanics of biodegradable versus titanium interference screw fixation for anterior cruciate ligament augmentation and reconstruction. Int Orthop. 2014;38:2499-503. https://doi.org/10.1007/ s00264-014-2483-y.

8. Ezechieli M, Ettinger M, Konig C, Weizbauer A, Helmecke P, Schavan R, Lucas A, Windhagen $\mathrm{H}$, Becher $\mathrm{C}$. Biomechanical characteristics of bioabsorbable magnesium-based (MgYREZr-alloy) interference screws with different threads. Knee Surg Sports Traumatol Arthrosc. 2016;24:3976-81. https://doi.org/10.1007/s00167-014-3325-6.

9. Wozniak TD, Kocabey Y, Klein S, Nyland J, Caborn DNM. Influence of thread design on bioabsorbable interference screw insertion torque during retrograde fixation of a soft-tissue graft in synthetic bone. Arthroscopy. 2005;21:815-9.
10. Ricci WM, Tornetta P 3rd, Petteys T, Gerlach D, Cartner J, Walker Z, Russell TA. A comparison of screw insertion torque and pullout strength. J Orthop Trauma. 2010;24:374-8. https://doi.org/10.1097/BOT.0b013e3181c4a655.

11. Brand JC, Pienkowski D, Steenlage E, Hamilton D, Johnson DL, Caborn DNM. Interference screw fixation strength of a quadrupled hamstring tendon graft is directly related to bone mineral density and insertion torque. Am J Sports Med. 2000;28:705-10.

12. Brown GA, Pena F, Grontvedt T, Labadie D, Engebretsen L. Fixation strength of interference screw fixation in bovine, young human, and elderly human cadaver knees: influence of insertion torque, tunnel-bone block gap, and interference. Knee Surg Sports Traumatol Arthrosc. 1996;3:238-44.

13. Jarvinen TLN, Nurmi JT, Sievanen H. Bone density and insertion torque as predictors of anterior cruciate ligament graft fixation strength. Am J Sports Med. 2004;32:1421-9. https://doi.org/10.1177/0363546503262168.

14. Martel O, Garces GL, Yanez A, Cuadrado A, Cardenes JF. Can an expansion device be used in anterior cruciate ligament reconstruction? An in vitro study of soft tissue graft tibial fixation. Knee. 2016;23:1049-54 doi: S09680160(16)30090-4.

15. Prado M, Martin-Castilla B, Espejo-Reina A, Serrano-Fernandez JM, Perez-Blanca A, Ezquerro F. Close-looped graft suturing improves mechanical properties of interference screw fixation in $\mathrm{ACL}$ reconstruction. Knee Surg Sports Traumatol Arthrosc. 2013;21:476-84 https://doi.org/10.1007/s00167-012-1975-9.

16. Honl M, Carrero V, Hille E, Schneider E, Morlock MM. Bone-patellar tendonbone grafts for anterior cruciate ligament reconstruction: an in vitro comparison of mechanical behavior under failure tensile loading and cyclic submaximal tensile loading. Am J Sports Med. 2002;30:549-57.

17. Markolf KL, Gorek JF, Kabo JM, Shapiro MS. Direct measurement of resultant forces in the anterior cruciate ligament - an invitro study performed with a new experimental-technique. J Bone Jt Surg-Am Volume. 1990;72A:557-67.

18. Brown CH Jr, Wilson DR, Hecker AT, Ferragamo M. Graft-bone motion and tensile properties of hamstring and patellar tendon anterior cruciate ligament femoral graft fixation under cyclic loading. Arthroscopy. 2004:20:922-35.

19. Camarda L, Pitarresi G, Moscadini S, Marannano G, Sanfilippo A, D'Arienzo $M$. Effect of suturing the femoral portion of a four-strand graft during an ACL reconstruction. Knee Surg Sports Traumatol Arthrosc. 2014;22:1040-6. https://doi.org/10.1007/s00167-013-2449-4.

20. Nagarkatti DG, McKeon BP, Donahue BS, Fulkerson JP. Mechanical evaluation of a soft tissue interference screw in free tendon anterior cruciate ligament graft fixation. Am J Sports Med. 2001;29:67-71.

21. Aga C, Rasmussen MT, Smith SD, Jansson KS, LaPrade RF, Engebretsen L, Wijdicks CA. Biomechanical comparison of interference screws and combination screw and sheath devices for soft tissue anterior cruciate ligament reconstruction on the tibial side. Am J Sports Med. 2013;41:841-8. https://doi.org/10.1177/0363546512474968.

22. Nye DD, Mitchell WR, Liu W, Ostrander RV. Biomechanical comparison of fixed-loop and adjustable-loop cortical suspensory devices for metaphyseal femoral-sided soft tissue graft fixation in anatomic anterior cruciate ligament reconstruction using a porcine model. Arthroscopy. 2017:33:1225. https://doi.org/10.1016/j.arthro.2016.12.014.

23. McDonald LS, Waltz RA, Carney JR, Dewing CB, Lynch JR, Asher DB, Schuett DJ, LeClere LE. Validation of varus stress radiographs for anterior cruciate ligament and posterolateral corner knee injuries: a biomechanical study. Knee. 2016;23:1064-8. https://doi.org/10.1016/j.knee.2016.07.001.

24. To JT, Howell SM, Hull ML. Contributions of femoral fixation methods to the stiffness of anterior cruciate ligament replacements at implantation. Arthroscopy. 1999;15:379-87. https://doi.org/10.1016/S0749-8063(99)70055-1.

25. Ishibashi Y, Rudy TW, Livesay GA, Stone JD, Fu FH, Woo SL. The effect of anterior cruciate ligament graft fixation site at the tibia on knee stability: evaluation using a robotic testing system. Arthroscopy. 1997;13:177-82.

26. Woo SL, Hollis JM, Adams DJ, Lyon RM, Takai S. Tensile properties of the human femur-anterior cruciate ligament-tibia complex. The effects of specimen age and orientation. Am J Sports Med. 1991;19:217-25.

27. Rowden NJ, Sher D, Rogers GJ, Schindhelm K. Anterior cruciate ligament graft fixation - initial comparison of patellar tendon and semitendinosus autografts in young fresh cadavers. Am J Sports Med. 1997;25:472-8. https://doi.org/10.1177/036354659702500409.

28. von der Heide N, Ebneter L, Behrend H, Stutz G, Kuster MS. Improvement of primary stability in $\mathrm{ACL}$ reconstruction by mesh augmentation of an established method of free tendon graft fixation. A 
biomechanical study on a porcine model. Knee. 2013;20:79-84. https:// doi.org/10.1016/j.knee.2012.09.015.

29. Giurea M, Zorilla P, Amis AA, Aichroth P. Comparative pull-out and cyclicloading strength tests of anchorage of hamstring tendon grafts in anterior cruciate ligament reconstruction. Am J Sports Med. 1999;27:621-5.

30. Nurmi JT, Sievänen $H$, Kannus $P$, Järvinen $M$, Järvinen TLN. Porcine tibia is a poor substitute for human cadaver tibia for evaluating interference screw fixation. Am J Sports Med. 2004;32:765-71.

31. Magen HE, Howell SM, Hull ML. Structural properties of six tibial fixation methods for anterior cruciate ligament soft tissue grafts. Am J Sports Med. 1999:27:35-43

32. Kousa $P$, Jarvinen $T L$, Vihavainen $M$, Kannus $P$, Jarvinen $M$. The fixation strength of six hamstring tendon graft fixation devices in anterior cruciate ligament reconstruction. Part I: femoral site. Am J Sports Med. 2003;31:174-81.

33. Hou S, Hsu C, Wang J, Chao C, Lin J. Mechanical tests and finite element models for bone holding power of tibial locking screws. Clin Biomech. 2004;19:738-45.

34. Donahue TLH, Gregersen C, Hull ML, Howell SM. Comparison of viscoelastic, structural, and material properties of double-looped anterior cruciate ligament grafts made from bovine digital extensor and human hamstring tendons. Journal of biomechanical engineering-transactions of the. Asme. 2001;123:162-9. https://doi.org/10.1115/1.1351889.

35. Coleridge SD, Amis AA. A comparison of five tibial-fixation systems in hamstring-graft anterior cruciate ligament reconstruction. Knee Surg Sports Traumatol Arthrosc. 2004;12:391-7. https://doi.org/10.1007/s00167-003-0488-y.

36. Dunkin BS, Nyland J, Duffee AR, Brunelli JA, Burden R, Caborn D. Soft tissue tendon graft fixation in serially dilated or extraction-drilled tibial tunnels: a porcine model study using high-resolution quantitative computerized tomography. Am J Sports Med. 2007;35:448-57.

Ready to submit your research? Choose BMC and benefit from:

- fast, convenient online submission

- thorough peer review by experienced researchers in your field

- rapid publication on acceptance

- support for research data, including large and complex data types

- gold Open Access which fosters wider collaboration and increased citations

- maximum visibility for your research: over $100 \mathrm{M}$ website views per year

At $\mathrm{BMC}$, research is always in progress.

Learn more biomedcentral.com/submissions 